\title{
CALPHAD-aided design of high entropy alloy to achieve high strength via precipitate strengthening
}

\author{
Lin Guo ${ }^{1}$, Ji Gu ${ }^{1 *}$, Xing Gong ${ }^{2}$, Song $\mathrm{Ni}^{1}$ and Min Song ${ }^{1 *}$
}

\begin{abstract}
Designing high entropy alloys (HEAs) with high strength and excellent ductility has attracted extensive scientific interest. In the present work, the CALPHAD (calculation of phase diagrams) method was applied to guide the design of an $(\mathrm{FeCoNi})_{92} \mathrm{Al}_{2.5} \mathrm{Ti}_{5.5}$ HEA strengthened by precipitation hardening. The grain size as well as the size and volume fraction of the precipitates was tailored via a thermomechanical process to optimize the mechanical properties. The uniformly dispersed nano-precipitates are $\mathrm{Ni}_{3}(\mathrm{Al}, \mathrm{Ti})$-type precipitates with an $L 1_{2}$ ordered structure presenting a fully coherent interface with the face-centered cubic (FCC) matrix. The yield strength of the alloy increases from 338.3 to 1355.9 $\mathrm{MPa}$ and the ultimate tensile strength increases from 759.3 to $1488.1 \mathrm{MPa}$, while the elongation maintains a reasonable value of $8.1 \%$. The striking enhancement of strength is mainly caused by the precipitate's hardening mechanism, which is evaluated quantitatively by various analytical models. The deformation-induced microbands and the coherent precipitates sheared by dislocations are the deformation and strengthening mechanisms contributing to the superior combination of ductility and strength in the present HEA. This investigation demonstrates that the CALPHAD method is beneficial to the design and optimization of HEAs.
\end{abstract}

Keywords: high entropy alloys, CALPHAD, precipitation, mechanical properties, dislocations

\section{INTRODUCTION}

High entropy alloys (HEAs), as a new class of metallic materials, are designed based on the strategy of maximizing the mixing configurational entropy, and have attracted considerable attention due to their promising properties [1-6]. The face centered cubic (FCC) HEAs display a superb ductility but normally a low strength, which can hardly meet the demands for practical structural applications $[4,6]$. Therefore, designing HEAs with both high strength and good ductility is essential. Several strengthening mechanisms, such as interstitial-solidsolution strengthening [7-9], phase-transformation strengthening [10], grain-boundary strengthening [11], and precipitations strengthening $[2,4,5]$, have been successfully applied to strengthen the FCC-based HEAs. Second-phase intermetallic compounds (IMCs) contribute significantly to the alloy properties and offer an efficient approach to enhance the strength of HEAs [12]. Thus, developing precipitation-strengthened HEAs is a promising approach for achieving high strength with good ductility. Two different types of precipitates, including intermetallic particles ( $\mu, \sigma$ phase) $[5,13]$ with incoherent phase boundaries to the matrix and coherent $\gamma$ ' phase particles with an $L 1_{2}$ superlattice structure [2,4], are used to develop precipitation-strengthened HEAs. The intermetallic particles strengthen the HEAs via the Orowan mechanism due to the hard and incoherent features, which results in high strength but low ductility [6]. On the other hand, the strengthening mechanism of the fine $\gamma$ ' phase is dominated by the particle shearing mechanism, and thus, the $\gamma$ ' phase can efficiently enhance the strength of the material without severely sacrificing its ductility $[2,4]$. The $\mathrm{Ni}_{3} \mathrm{Al}$-type $\gamma^{\prime}$ phase has been found to be an important strengthening phase in FCC-based HEAs, which could achieve a good balance between ductility and strength $[2,4]$.

The key advantage of HEAs is that they provide almost infinite possibilities in designing alloys. While characterizing all candidate alloys is time-consuming and realistically impossible, the well-developed CALPHAD method offers an option to greatly accelerate the alloy designing process; for example, Zhang et al. [14] applied the CALPHAD method to design Nb-bearing austenitic steels with optimized contents of added $\mathrm{C}$ and $\mathrm{N}$. The effects of alloying element, $\mathrm{Nb}$, on the phase constitution

\footnotetext{
${ }^{1}$ State Key Laboratory of Powder Metallurgy, Central South University, Changsha 410083, China

${ }^{2}$ College of Physics and Optoelectronic Engineering, Shenzhen University, Shenzhen 518060, China

* Corresponding authors (emails: guji9219@csu.edu.cn (Gu J); msong@csu.edu.cn (Song M))
} 
in $\mathrm{Nb}_{x}(\mathrm{NbTiZr})_{100-x}$ quaternary alloy systems was also identified by the CALPHAD approach [15]. He et al. [16] used the CALPHAD approach to predict the phase diagram of the $(\mathrm{CoCrFeNi})_{100-x-y} \mathrm{Ti}_{x} \mathrm{Al}_{y}$ (at.\%) alloy system, and the predicted data agreed well with the experimental results.

In the present work, we integrated the CALPHADprediction and experimental-validation approaches to design precipitation-strengthened HEAs. To optimize the strength and ductility in precipitation-strengthened HEAs, the grain size as well as the size and volume fraction of the precipitates was tailored through a thermo-mechanical process. The coherent $L_{2}$ nanoprecipitate is uniformly distributed in the FCC matrix after the proper thermo-mechanical process. The present work demonstrates that the CALPHAD method can aid the design of precipitation-strengthened HEAs to achieve high yield strength and ultimate tensile strength (UTS) while maintaining a reasonable ductility.

\section{EXPERIMENTAL SECTION}

In the present study, the CALPHAD method was applied to guide alloy design. The phase diagram of $(\mathrm{FeCoNi})_{92^{-}}$ $\mathrm{Al}_{2.5} \mathrm{Ti}_{5.5}$ was firstly calculated using the Thermo-Cal software with the ThermoTech Ni-based database TTNI8 to guide the thermo-mechanical process and obtain a proper number of $\gamma$ ' precipitates, as shown in Fig. 1. The $\mathrm{Ni}_{3} \mathrm{Al}$-type $\gamma^{\prime}$ phase was chosen as the strengthening phase. A certain amount of $\mathrm{Fe}$ and $\mathrm{Co}$ can dissolve into the $\mathrm{Ni}_{3} \mathrm{Al}$-type $\gamma$ ' phase, which help to enhance the intrinsic ductility of the $\gamma^{\prime}$ phase. Since $\mathrm{Al}$ and $\mathrm{Ti}$ are the $\gamma^{\prime}$ phase-forming elements [4], a certain amount of $\mathrm{Al}$ and Ti were added to the equiatomic FeCoNi alloy to form the $\gamma$ ' phase.

The ingots with a nominal chemical composition of $(\mathrm{FeCoNi})_{92} \mathrm{Al}_{2.5} \mathrm{Ti}_{5.5}$ (at.\%) were prepared by arc-melting high purity $\mathrm{Fe}, \mathrm{Co}, \mathrm{Ni}, \mathrm{Al}$, and $\mathrm{Ti}$ (above 99.8\%) under $\mathrm{Ar}$ atmosphere. The actual chemical composition is shown in Table 1, analyzed by inductively coupled plasma mass spectroscopy (ICP-MS). The as-cast alloy was homogenized at $1200^{\circ} \mathrm{C}$ for $4 \mathrm{~h}$, followed by various thermomechanical procedures to obtain four kinds of specimens (designated as T1, T2, T3, and T4, respectively) with different grain sizes and different volume fractions and sizes of the precipitates. The T1 specimen was cold-rolled to a $60 \%$ reduction in thickness, followed by annealing at $1150^{\circ} \mathrm{C}$ for $10 \mathrm{~min}$ to obtain coarse-grained structures without precipitates. The T2 and T3 specimens were initially cold-rolled to an $85 \%$ reduction in thickness and subsequently annealed at $1150^{\circ} \mathrm{C}$ for $3 \mathrm{~min}$. Then, the

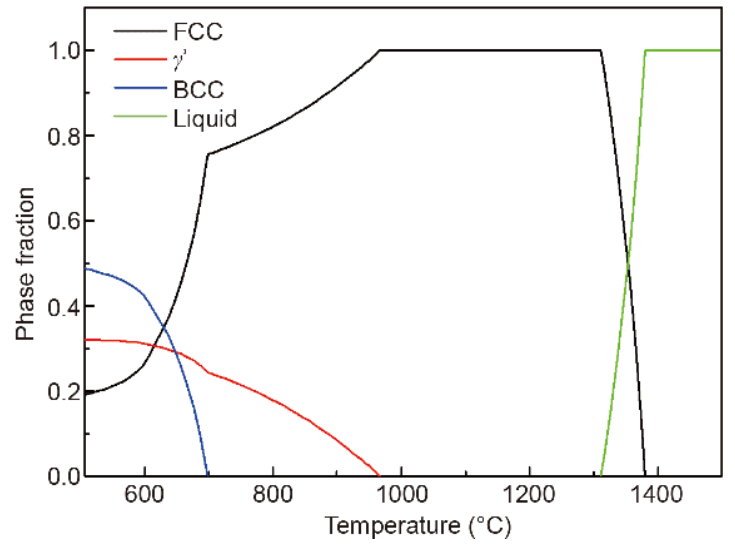

Figure 1 Phase diagram of the $(\mathrm{FeCoNi})_{92} \mathrm{Al}_{2.5} \mathrm{Ti}_{5.5}$ HEA calculated using Thermo-Calc software and the TTNI8 database.

Table 1 Chemical compositions and the basic properties of the elements [17] in $(\mathrm{FeCoNi})_{92} \mathrm{Al}_{2.5} \mathrm{Ti}_{5.5}$ alloy

\begin{tabular}{cccccc}
\hline Element & $\mathrm{Fe}$ & $\mathrm{Co}$ & $\mathrm{Ni}$ & $\mathrm{Al}$ & $\mathrm{Ti}$ \\
\hline $\begin{array}{c}\text { at.\% } \\
\text { Atomic } \\
\text { radius }(\AA)\end{array}$ & 33 & 28.8 & 30.3 & 2.5 & 5.4 \\
$\begin{array}{c}\text { Melting } \\
\text { temperature }\left({ }^{\circ} \mathrm{C}\right)\end{array}$ & 1535 & 1495 & 1453 & 660 & 1660 \\
\hline
\end{tabular}

annealed specimens were aging treated at 800 and $750^{\circ} \mathrm{C}$ for $1 \mathrm{~h}$, respectively. The T4 specimen was initially coldrolled to an $85 \%$ reduction in thickness and subsequently annealed at $970^{\circ} \mathrm{C}$ for $0.5 \mathrm{~min}$. Then, the annealed specimens were aging treated at $750^{\circ} \mathrm{C}$ for $1 \mathrm{~h}$. The detailed processing conditions and the grain size of the four specimens are shown in Table 2. All the thermo-mechanical procedures were performed in air and followed by water quenching. Doge-bone-shaped specimens with a gauge length of $24 \mathrm{~mm}$ were machined for the tensile tests. The surfaces of the tensile samples were grounded from 180 to 2000 grit using silicon carbide paper. The tensile tests were performed using an Instron 3369 testing machine with a strain rate of $1.4 \times 10^{-3} \mathrm{~s}^{-1}$ at room temperature.

The phase constitution was identified by $\mathrm{X}$-ray diffraction (XRD) (a Dmax 2500VB equipment) using $\mathrm{Cu}$ $\mathrm{Ka}$ radiation. Microstructure characterizations were performed using a scanning electron microscope (SEM, FEI Helios NanoLab G3 UC) equipped with an electron backscatter diffraction (EBSD) detector and a transmission electron microscope (TEM, Tecnai G2 F20 operating at $200 \mathrm{kV}$ ) equipped with an X-ray energy-dispersive spectroscopy (EDS) instrument. The TSL OIM ${ }^{\mathrm{TM}}$ software was used to measure the grain size and acquire 
Table 2 Grain size, yield strength, ultimate tensile strength and elongation of the alloy after different treatments processing

\begin{tabular}{|c|c|c|c|c|c|}
\hline Alloys & Treatment processing & Grain size $(\mu \mathrm{m})$ & Yield strength $(\mathrm{MPa})$ & $\begin{array}{l}\text { Ultimate tensile } \\
\text { strength }(\mathrm{MPa})\end{array}$ & Elongation (\%) \\
\hline $\mathrm{T} 1$ & $\begin{array}{l}\text { Cold rolled }(60 \%)+\text { annealing at } \\
1150^{\circ} \mathrm{C} \text { for } 10 \mathrm{~min}\end{array}$ & 135.7 & 338.3 & 759.3 & 60.4 \\
\hline $\mathrm{T} 2$ & $\begin{array}{l}\text { Cold rolled }(85 \%)+\text { annealing at } \\
1150^{\circ} \mathrm{C} \text { for } 3 \mathrm{~min}+\text { aging at } 800^{\circ} \mathrm{C} \\
\text { for } 60 \mathrm{~min}\end{array}$ & 93.6 & 576.5 & 1112 & 30.7 \\
\hline T3 & $\begin{array}{c}\text { Cold rolled }(85 \%)+\text { annealing at } \\
1150^{\circ} \mathrm{C} \text { for } 3 \mathrm{~min}+\text { aging at } 750^{\circ} \mathrm{C} \\
\text { for } 60 \mathrm{~min}\end{array}$ & 87.7 & 881.7 & 1267.7 & 19.8 \\
\hline $\mathrm{T} 4$ & $\begin{array}{l}\text { Cold rolled }(85 \%)+\text { annealing at } \\
970^{\circ} \mathrm{C} \text { for } 0.5 \mathrm{~min}+\text { aging at } 750^{\circ} \mathrm{C} \\
\text { for } 60 \mathrm{~min}\end{array}$ & 1.4 & 1355.9 & 1488.1 & 8.1 \\
\hline
\end{tabular}

pseudo-colored orientation imaging microscopy (OIM) grain maps. For the SEM and EBSD observations, the specimens were electrochemically polished in a mixed solution of perchloric acid (10 vol.\%) and ethanol $(10 \mathrm{vol} . \%)$ at a direct voltage of $30 \mathrm{~V}$ and a temperature of $-30^{\circ} \mathrm{C}$. For the TEM analysis, foils with a thickness of $80 \mu \mathrm{m}$ were initially twin-jet electropolished in a mixture of perchloric acid (5 vol.\%) and ethanol (95 vol.\%), at a voltage of $20 \mathrm{~V}$ and a temperature of $-35^{\circ} \mathrm{C}$, and then ion-milled for $20 \mathrm{~min}$. A statistical analysis of the size of the $L 1_{2}$ precipitates was performed for a sample of 1000 particles using the ImageJ software [18].

\section{RESULTS}

\section{XRD and SEM analyses}

Fig. 2 shows the XRD patterns of the $(\mathrm{FeCoNi})_{92} \mathrm{Al}_{2.5} \mathrm{Ti}_{5.5}$ HEA after different thermo-mechanical treatments. Peaks of the FCC phase are obvious for all samples. No superlattice peak (e.g., (001)), a sign of ordered phase, was detected in the XRD patterns. Later, the TEM observa-

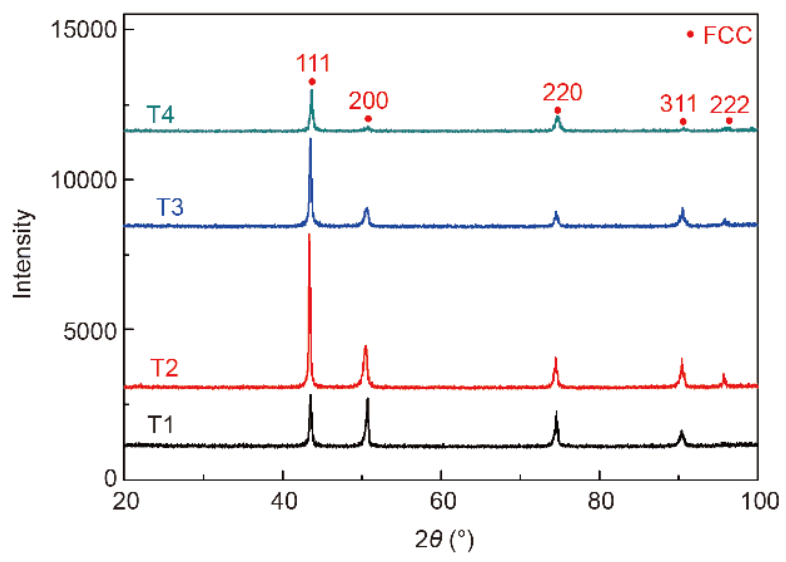

Figure 2 XRD patterns of the $(\mathrm{FeCoNi})_{92} \mathrm{Al}_{2.5} \mathrm{Ti}_{5.5}$ HEA after different treatments. tions indicate the existence of ordered $L 1_{2}$ precipitates in the T2, T3, and T4 alloys. The missing superlattice peaks are due to a relatively small scattering-factor difference between the precipitates and the matrix, which arises from the complicate atomic occupation in the ordered phase and the peak-broadening effect from nano-sized precipitates [19].

The EBSD inverse-pole-figure (IPF) maps shown in Fig. 3 demonstrate the evolution of the grain size after different thermo-mechanical treatments. The grain sizes of the alloys are listed in Table 2. The grain size was refined from $135.7 \mu \mathrm{m}$ for the T1 alloy to $1.4 \mu \mathrm{m}$ for the T4 alloy. Except for the fine grain structure, non-recrystallized areas exist in the T4 alloy as well. The partial recrystallized structure was further characterized by a combination of grain boundary and kernel average misorientation (KAM) maps shown in Fig. 4. Nonrecrystallization regions with elongated lager grains are in the IPF map (Fig. 3d), which retains plenty of low angle boundaries (highlighted by red lines in Fig. 4b) and very high KAM values (Fig. 4a). The recovery occurs in these non-recrystallization regions during annealing, causing the formation of substructures (higher KAM values and more low-angle boundaries are evident). These substructures are formed due to the dislocation interaction and annihilation during the recovery process [20].

Fig. 5 shows the corresponding SEM micrographs for these four kinds of specimens. Only very few particles were found in the $\mathrm{T} 1$ alloy. In contrast, a large number of nanosized precipitates were uniformly distributed within the grain matrix in the T2, T3, and T4 alloys, as shown in Fig. 5b-d. This is consistent with the phase diagram prediction (Fig. 1). Fig. 6 shows the size distribution of the precipitates and the particle spacing in the $\mathrm{T} 2, \mathrm{~T} 3$, and $\mathrm{T} 4$ alloys. The average sizes of the precipitates in the T2, $\mathrm{T} 3$, and $\mathrm{T} 4$ alloys are $33.6,18.9$, and $25.4 \mathrm{~nm}$, respectively, and the precipitates' spacings in the $\mathrm{T} 2, \mathrm{~T} 3$, and $\mathrm{T} 4$ alloys 


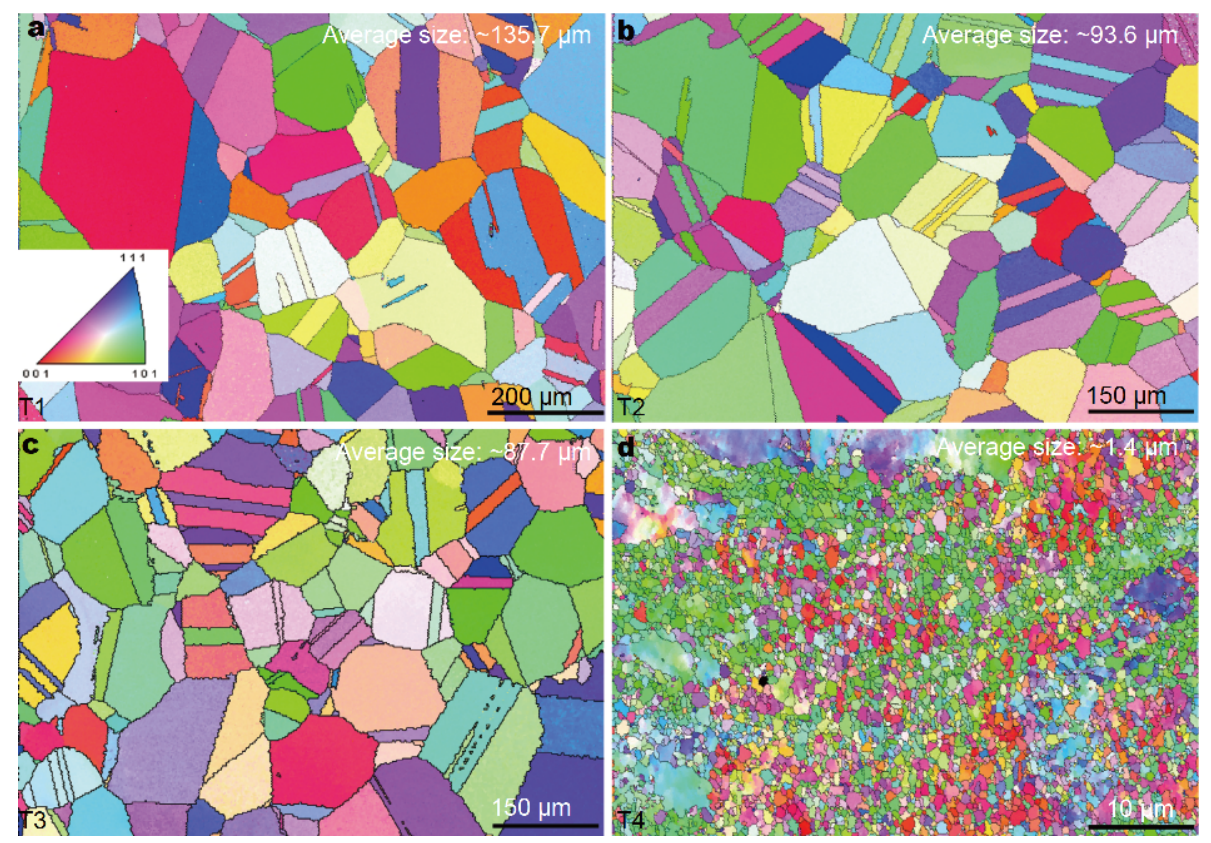

Figure 3 EBSD IPF maps illustrating the grain-size evolution after different thermo-mechanical processes.

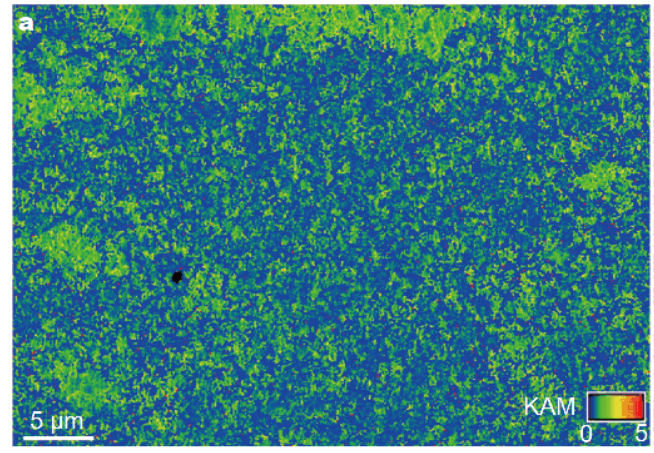

Figure 4 (a) KAM map and (b) grain-boundaries map of the T4 alloy.

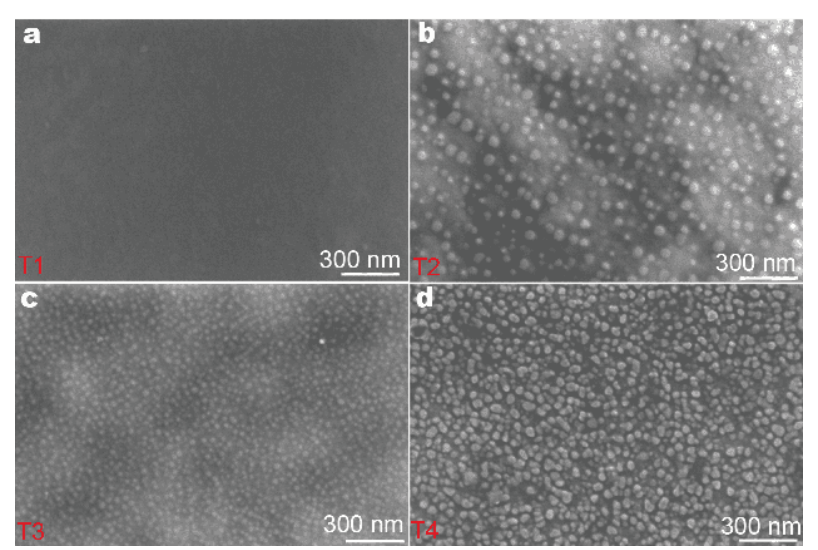

Figure 5 SEM micrographs of the: (a) T1, (b) T2, (c) T3, and (d) T4.

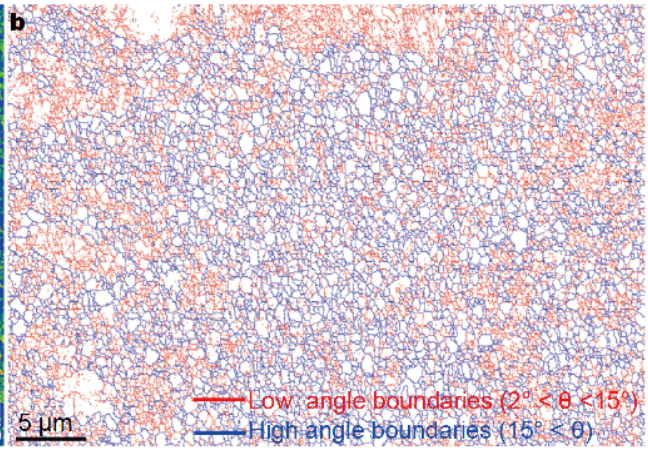

were measured to be $39.5,13.9$, and $15.0 \mathrm{~nm}$, respectively. The volume fraction of the precipitates in the T2, T3, and T4 alloys are $14.9 \%, 20.6 \%$, and $25.6 \%$, respectively. The largest size and lowest volume fraction of the precipitates in the T2 alloy is due to the high temperature-aging treatment $\left(800^{\circ} \mathrm{C}\right)$. Although the $\mathrm{T} 3$ and $\mathrm{T} 4$ alloys were submitted to the same temperature during the aging treatment (i.e., $750^{\circ} \mathrm{C}$ ), the pre-existing dislocations (substructure) in the T4 alloy can promote the nucleation and coarsening of the precipitate, resulting in larger size and volume fraction of the precipitates in the T4 alloy.

\section{TEM characterization}

The dark-field TEM image of the T2 alloy in Fig. $7 \mathrm{a}$ 

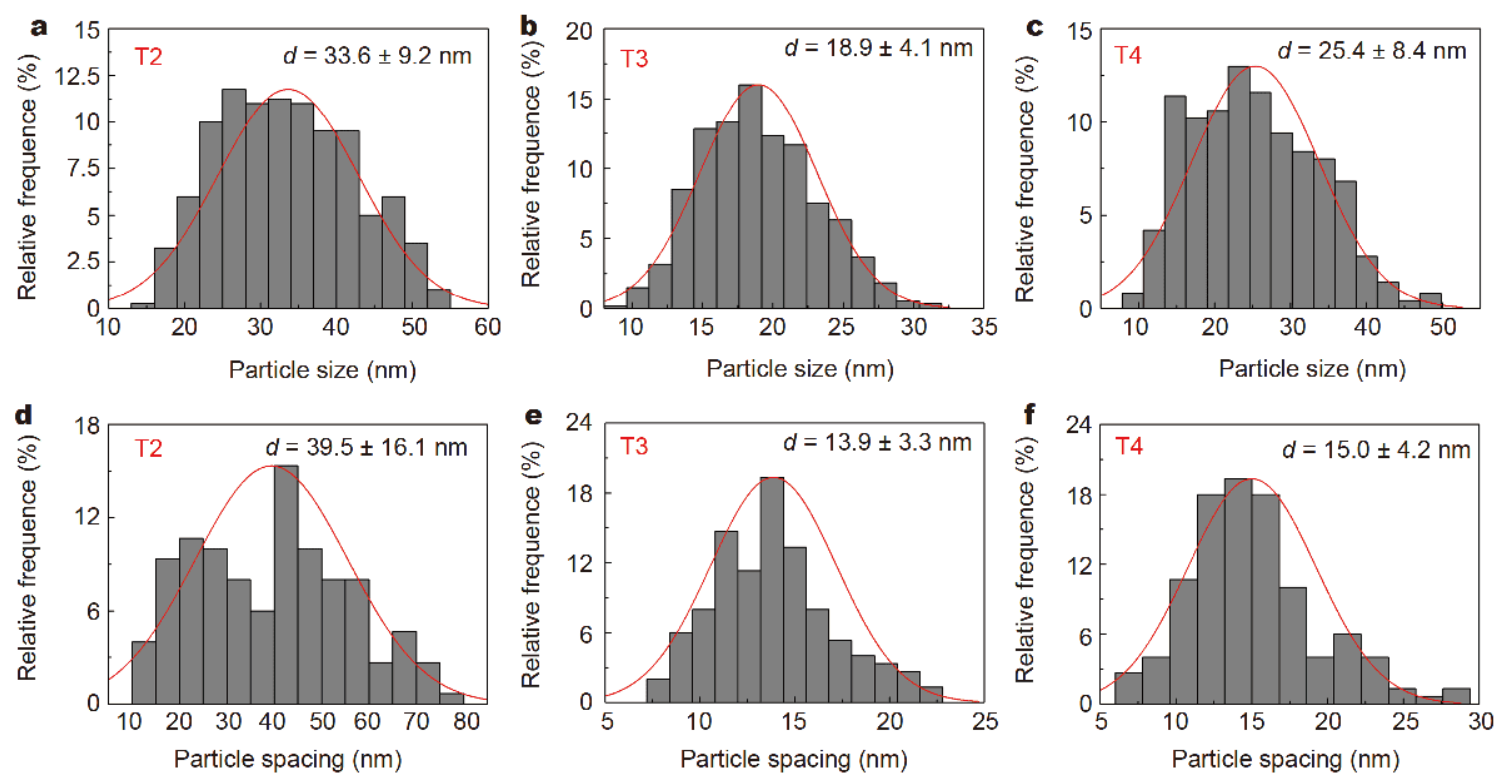

Figure 6 Particle-size and spacing distributions of the $L 1_{2}$ ordered precipitates in the (a,d) T2, (b, e) T3, and (c, f) T4 samples.

clearly shows the uniformly distributed nanosized precipitates in the FCC matrix. The corresponding selected area electron diffraction (SAED) pattern (inset in Fig. 7a) demonstrates that these precipitates have an ordered $L 1_{2}$ structure. Fig. $7 \mathrm{~b}$ shows a high-resolution TEM (HRTEM) image of a precipitate in the T2 alloy, taken
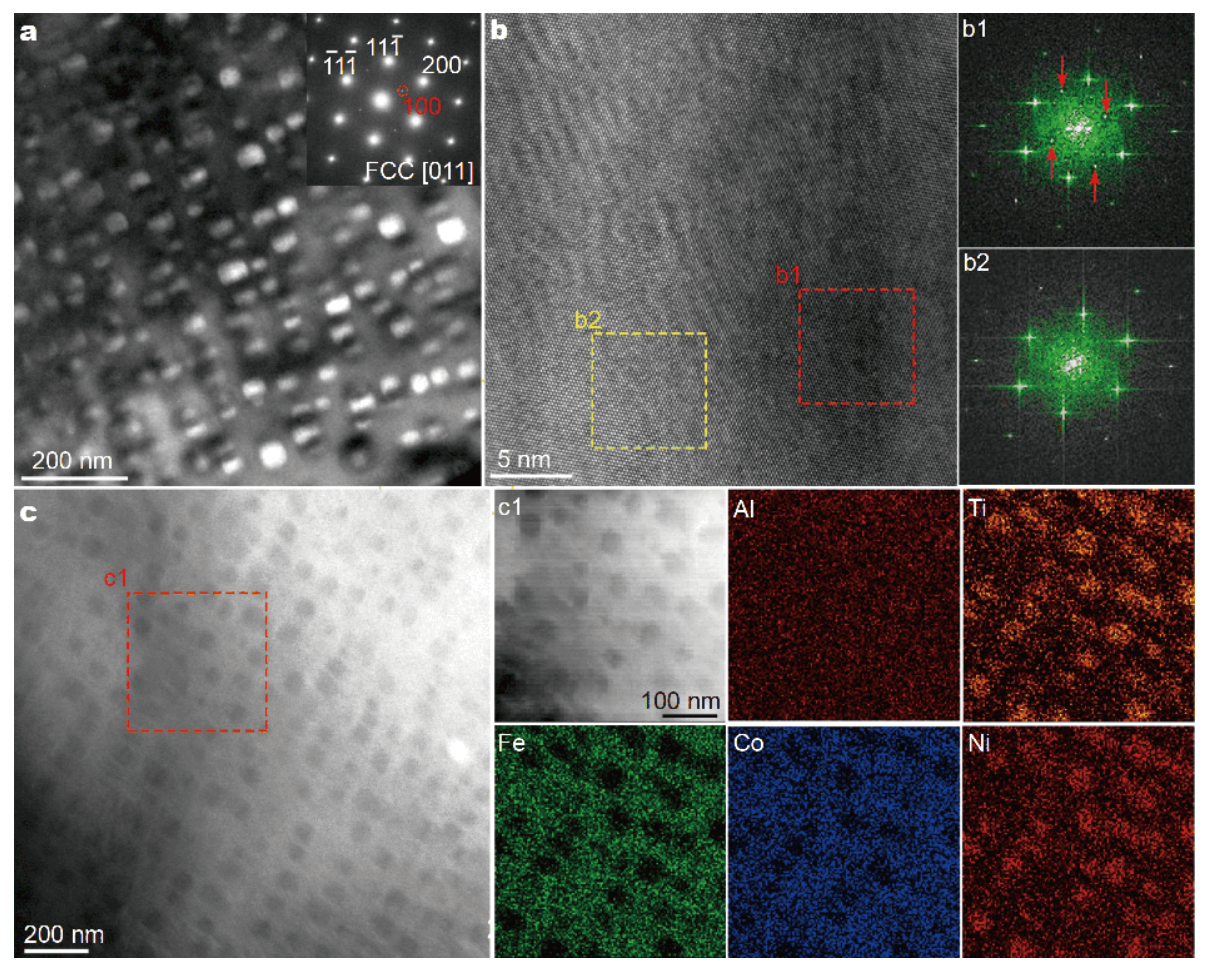

Figure 7 TEM characterizations of the T2: (a) TEM dark-field image and corresponding SAED pattern, (b) HRTEM image of the precipitates and corresponding FFT pattern (the superlattice spots are outlined by red arrows), (c) HAADF STEM image and (c1) corresponding elemental mapping in the red-square region in $(c)$. 
along the $[011]_{\text {FCC }}$ crystallographic direction. Fast Fourier transformation (FFT) patterns from the red and yellow square regions in Fig. $7 \mathrm{~b}$ confirm the structure of FCC and $L 1_{2}$, respectively. Besides, the precipitate and the matrix present a fully coherent interface. The lattice parameters of the FCC structure and the ordered $L 1_{2}$ structure are 0.359 and $0.360 \mathrm{~nm}$, respectively, calculated from the distance between two $\{111\}$ planes in the HRTEM-filtered image. The lattice parameter mismatch between the matrix and the precipitate is only $0.28 \%$, and such a low value accounts for the formation of a coherent interface [21]. This also explains why the superlattice spots cannot be detected by XRD. Fig. 7c shows a highangle annular dark-field (HAADF) scanning TEM (STEM) image of the T2 and the corresponding elemental mapping from the red square region. $\mathrm{Ti}$ and $\mathrm{Ni}$ elements are preferentially segregated in the $L 1_{2}$ precipitates. The matrix is enriched in Fe and Co. The TEM images (Fig. 7 and Fig. S1) and the elemental distribution indicate that the precipitates are the $\mathrm{Ni}_{3}(\mathrm{Ti}, \mathrm{Al})$-type $L 1_{2}$ phase.

\section{Mechanical properties at room temperature}

Fig. 8 shows representative engineering strain-stress curves for the four specimens at room temperature. The corresponding values of the yield strength, UTS, and tensile elongation are listed in Table 2. Owing to its single-phase structure and coarse grain size, the T1 exhibits the lowest yield strength $(338.3 \mathrm{MPa})$ and UTS (759.3 MPa) but the highest elongation (60.4\%) compared with other specimens. The alloys with finer grain sizes and precipitates show a higher yield strength and UTS. As a result, the T4 exhibits a striking enhancement in the mechanical properties; for example, the yield strength increases from 338.3 to $1355.9 \mathrm{MPa}$ and the UTS increases from 759.3 to $1488.1 \mathrm{MPa}$, due to the high density and uniformly dispersed precipitates as well as the fine grains $(1.4 \mu \mathrm{m})$. The superior combination of yield strength (1355.9 MP), UTS (1488.1 MPa), and ductility (tensile elongation of $8.1 \%$ ) of the T4 is mainly ascribed to grain boundary strengthening and precipitates strengthening.

\section{Microstructural evolution during tensile deformation}

Fig. 9 shows the deformation microstructures of the T1 at low (2\%), medium (30\%), and high (60\%) strains. Pile-up dislocations gliding along the primary crystallographic direction were detected at a low strain of $2 \%$ (Fig. 9a), which was a representative planar glide configuration. When the sample was deformed to about $30 \%$, as shown in Fig. 9b, planar dislocation arrays appeared in the dense

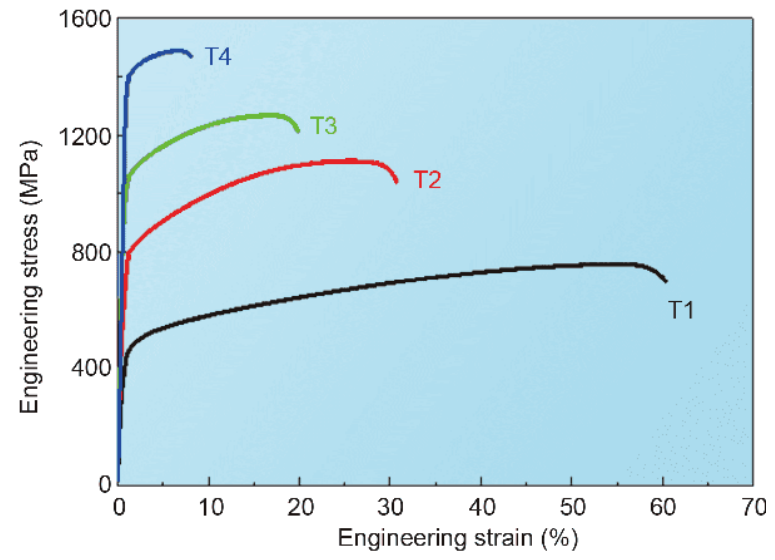

Figure 8 Engineering strain-stress curves of the four specimens tensiledeformed at room temperature.

dislocation networks due to the activation of two noncoplanar slip systems. Such a dislocation configuration is the so-called Taylor lattice (TL) structure, a kind of low energy dislocation structure against dislocation cells formed by a wavy glide [22-24]. These dislocation configurations indicate the pronounced planar glide in the T1. At a high strain ( $60 \%)$, well-developed microbands (MBs) were observed, as seen in Fig. 9c. Moreover, wellrefined nanograins were also observed near the $\mathrm{MB}$ region. This is revealed by the corresponding SAED pattern, which shows a set of distinctive continuous rings. As the strain increases, the TLs rotate to activate different slip systems for accommodating the strain [23]. Then, more MBs will be formed and refined for compensating the geometrical requirement caused by this resultant rotation [23]. Since the MBs preferentially end at low energy location, such as at grain boundaries and other MBs, the grains will be subdivided by their intersections at a high strain, resulting in the formation of nanograins (Fig. 9c) $[23,25]$. The grain subdivisions and refinement formed by dislocation substructure at a high strain can enhance the strength by the dynamic Hall-Petch effect.

Fig. 10 shows the deformation microstructure of the T2 at different strains. At a low strain $(\sim 2 \%)$, the dislocation band observed in Fig. 10a indicates a planar glide of dislocations. Since uniformly dispersed nano-precipitates with an atomically ordered structure are beneficial to the planar glide of dislocations, a similar dislocation configuration is often observed in precipitate-strengthening FCC alloys $[21,26]$. The microstructure of the specimen deformed to fracture $(\sim 28 \%)$ presents well-developed MBs. Mechanical twinning and transformation induced martensite were not detected in this alloy, which is similar to the $\mathrm{T} 1$. 


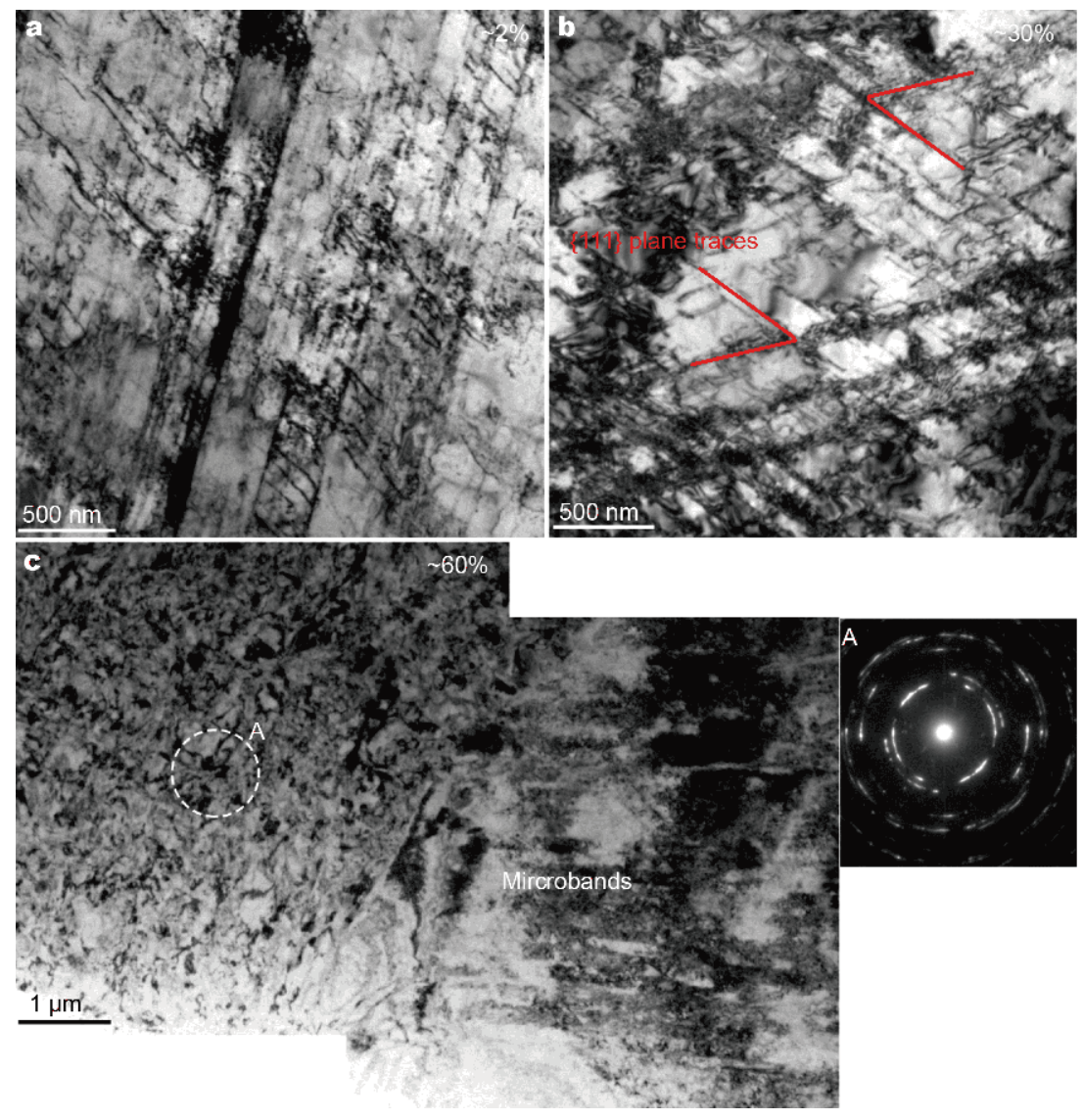

Figure 9 TEM micrographs showing the microstructures of the T1 at different strains: (a) $2 \%$, (b) $30 \%$, and (c) $60 \%$.

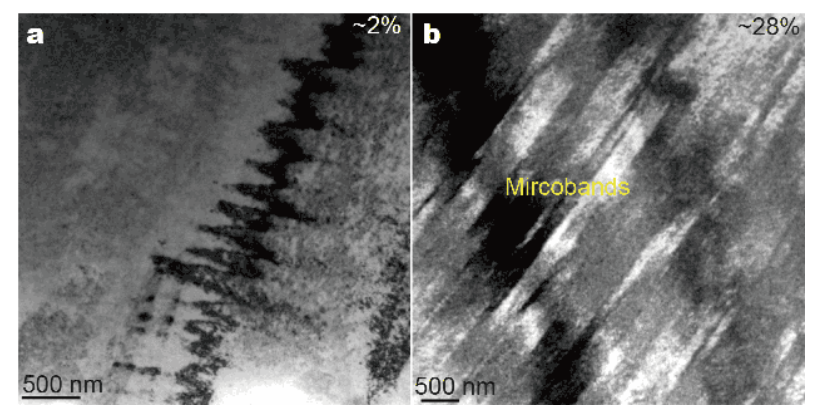

Figure 10 TEM micrographs showing the microstructures of the T2 alloy at different strains: (a) $2 \%$ and (b) $28 \%$.

The interaction between precipitates and the dislocation observed at a tensile strain of about $28 \%$ were further analyzed by HRTEM, as shown in Fig. 11. The precipitates-matrix interface was identified by the corresponding FFT patterns of the four regions (A, B, C, D) in Fig. 11a, outlined by a yellow dashed line. Regions $A$ and $\mathrm{B}$ are confirmed to be the FCC matrix, while regions $\mathrm{C}$ and $\mathrm{D}$ are determined to be the $L 1_{2}$ ordered structure.
The irregular interface indicates the occurrence of dislocation cutting through the precipitates. Fig. 11b shows the HRTEM-filtered image. The corresponding inverseFFT (IFFT) patterns for the (11-1) and (1-11) planes are shown in Fig. 11c and d, respectively. Numerous dislocations-denoted as " $\mathrm{T}$ "- are found at the interface and inside precipitates, which demonstrate dislocation shearing of the precipitates during deformation.

\section{DISCUSSION}

\section{Phase constitution}

In general, the formation of multi-component solidsolution phases in HEAs should satisfy the empirical criteria, that is, $\delta \leq 6.6 \%$ and $\Omega \geq 1.1$, where $\Omega$ is an integrated parameter referring to $\Delta S_{\text {mix }}$ (entropy of mixing), $T_{\mathrm{m}}$ (melting point), and $\Delta H_{\text {mix }}$ (enthalpy of mixing), and $\delta$ is the atomic-size difference of the constituent elements [27]. $\delta, \Omega, \Delta S_{\text {mix }}$ and $\Delta H_{\text {mix }}$ are defined as follows [27]:

$\delta=\sqrt{\sum_{i=1}^{n} c_{i}\left(1-r_{i} / r_{\mathrm{avg}}\right)^{2}}, r_{\mathrm{avg}}=\sum_{i=1}^{n} c_{i} r_{i}$ 

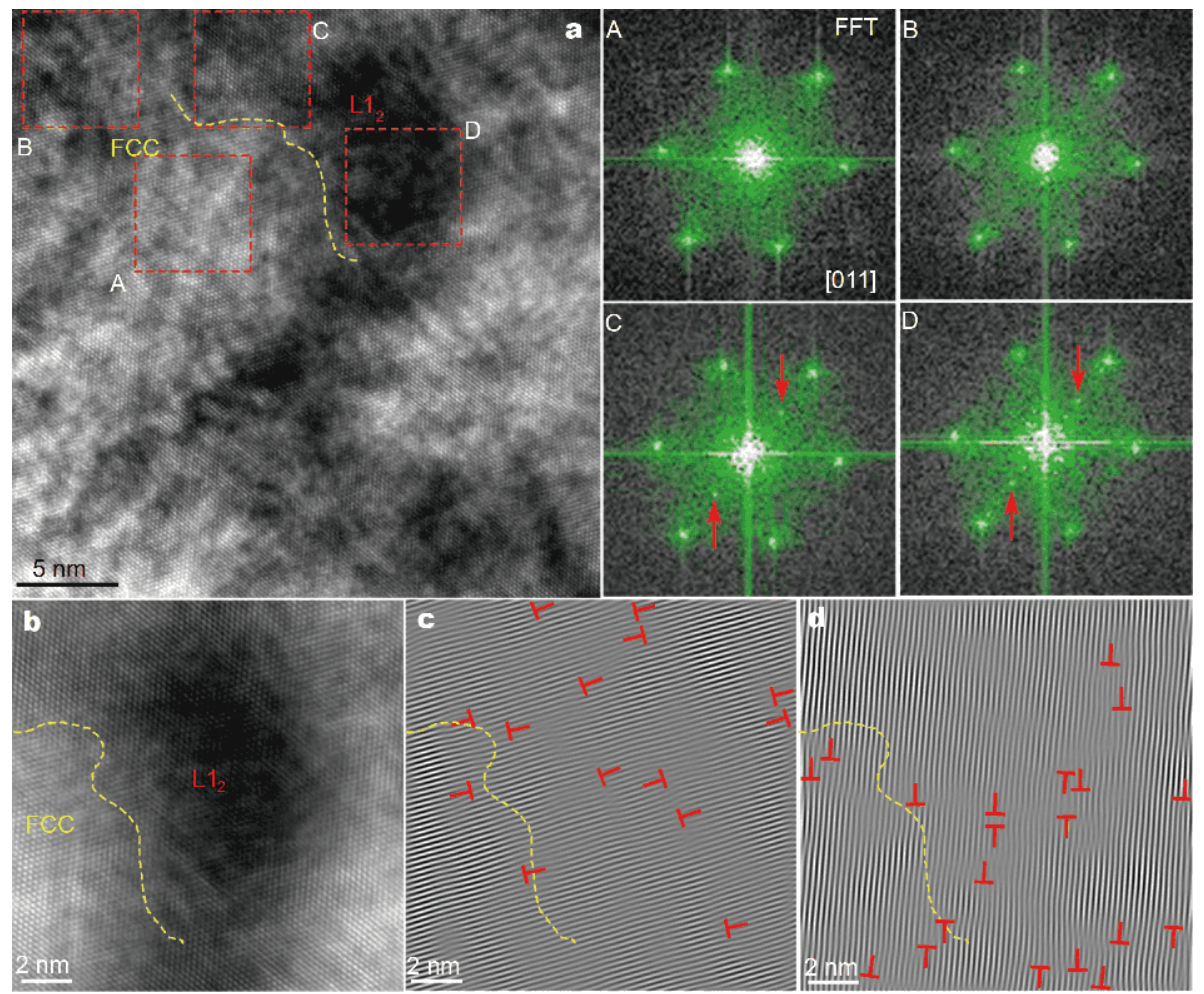

Figure 11 (a) HRTEM image of the T2 tensile-deformed to fracture (with a total strain of about $28 \%$ ), with the interface between the matrix and the precipitate being identified by the corresponding FFT pattern A, B, C, and D (the superlattice spots are outlined by red arrows), (b) HRTEM-filtered image of the precipitate-matrix interface, and (c, d) corresponding IFFT images of the HRTEM shown in (b) for the (11-1) and (1-11) planes.

$\Omega=\frac{T_{\mathrm{m}} \mathbf{\Lambda} S_{\text {mix }}}{\left|\Delta H_{\text {mix }}\right|}$

$\Delta S_{\text {mix }}=-R \sum_{i=1}^{n}\left(c_{i} \ln c_{i}\right), \sum_{i=1}^{n} c_{i}=1$,

$\Delta H_{\text {mix }}=\sum_{i=1, i \neq j}^{n} 4 H_{i j}^{\text {mix }} c_{i} c_{j}$,

$T_{\mathrm{m}}=\sum_{i=1}^{n} c_{i}\left(T_{\mathrm{m}}\right)_{i}, \sum_{i=1}^{n} c_{i}=1$,

where $r_{i}$ and $\left(T_{\mathrm{m}}\right)_{i}$ are the atomic radius and melting point of the $i$ th component, respectively, $H_{i j}^{\text {mix }}$ is the enthalpy of mixing of the $i$ th and $j$ th components, calculated by Miedema model, and $R=8.314 \mathrm{~J} \mathrm{~K}^{-1} \mathrm{~mol}^{-1}$ is the gas constant. When $\Omega$ is infinitely close to the critical value 1.1, coherent precipitates can form in the matrix [28]. The enthalpy of mixing $\left(H_{i j}^{\mathrm{mix}}\right)$, atomic radius, and melting points of the five elements are shown in Tables 1 and 3 [29]. The values of $\delta$ and $\Omega$ are $3.8 \%$ and 1.179, respectively, derived from the above equations. The enthalpy of mixing for the atom pair $\mathrm{Al} / \mathrm{Ti}$ is the most negative one $\left(-30 \mathrm{~kJ} \mathrm{~mol}^{-1}\right)$, which indicates their good affinity for
Table 3 The values of chemical mixing enthalpy, $\Delta H_{\text {mix }}\left(\mathrm{kJ} \mathrm{mol}^{-1}\right)$, of atomic pairs between elements $\mathrm{Fe}, \mathrm{Co}, \mathrm{Ni}, \mathrm{Al}$, and $\mathrm{Ti}$ [29]

\begin{tabular}{cccccc}
\hline Element & $\mathrm{Fe}$ & $\mathrm{Co}$ & $\mathrm{Ni}$ & $\mathrm{Al}$ & $\mathrm{Ti}$ \\
\hline $\mathrm{Fe}$ & 0 & -1 & -2 & -11 & -17 \\
$\mathrm{Co}$ & & 0 & 0 & -19 & -28 \\
$\mathrm{Ni}$ & & & 0 & -22 & -35 \\
$\mathrm{Al}$ & & & & 0 & -30 \\
\hline
\end{tabular}

each other. In addition, $\mathrm{Al}$ and $\mathrm{Ti}$ preferentially form intermetallic phases with $\mathrm{Fe}, \mathrm{Ni}$, and $\mathrm{Co}$ because they exhibit negative enthalpies of mixing for different atom pairs, including pairs with $\mathrm{Fe}, \mathrm{Co}$, and $\mathrm{Ni}$, as seen in Table 3. A small amount of $\mathrm{Al}$ and $\mathrm{Ti}$ benefit the formation of a strong $\gamma$ ' phase $\left(L 1_{2}\right)$ in FeCoCrNi HEAs $[2,4]$. According to the above analysis, a solid-solution phase and coherent precipitates can be formed in the present alloy system. The experimental results are in good agreement with the values predicted by the CALPHAD method. The $\gamma^{\prime}\left(L 1_{2}\right)$ phase precipitates within the FCC matrix when the alloy is annealed at 750 and $800^{\circ} \mathrm{C}$. In addition, the experimental results show that the volume fraction of the $L 1_{2}$ phase decreases with increasing an- 
nealing temperature, consistent with the predicted results. Although there is a small deviation between the experimental data and the predicted results in the volume fraction of the precipitates, the CALPHAD method is a reliable tool to evaluate the phase constitution and stability in multicomponent alloy systems.

\section{Evolution of deformation microstructure}

As shown in Figs 9 and 10, no distinct cell structures, mechanical twinning or transformation induced martensite are in the present HEAs, and their absence is due to the high stacking fault energies of the matrix alloy [30]. Furthermore, the formation of nano-precipitates can enhance the resolved stress for twinning, resulting in the retardation of twinning [12,31]. In contrast, well-developed MBs were obtained at high strains. At the onset of plastic deformation, it is beneficial to activating the planar slip due to the presence of a short- or long-range ordered phase $\left(L 1_{2}\right)$, resulting in glide-plane softening $[21,32,33]$. Due to the dislocation propagating throughout the glide plane, initial slip bands are formed, which will further go through the grain. Upon increasing the strain, dislocation pile-ups occur, which increases the back stress. Thus, more dislocations are produced and emitted inside the slip bands [32]. Consequently, a well-developed slip band referred to as a MB is formed. The MBs formed by planar glide are similar to the low-angle grain boundaries and provide an additional work-hardening source to accommodate the imposed strain at high strain, which stabilizes the plastic deformation $[23,34,35]$. The nano-precipitates produce hardening through either the Orowan bowing or the dislocation-shearing mechanism, depending on the interaction between precipitates and moving dislocations [36,37]. The precipitates are sufficiently small and coherent, causing a dislocation-shearing mechanism (Fig. 11). In the present alloy, the precipitates have an average size of about $30 \mathrm{~nm}$ and are coherent with the matrix. The results of the HRTEM analysis (Fig. 11) indicate that the precipitation hardening in the present alloy is dominated by the dislocation-shearing mechanism.

\section{Strengthening mechanisms}

Compared with the matrix alloy (i.e., T1 without precipitates), the pronounced increase in the yield strength $\left(\Delta \sigma_{0.2}\right)$ for the T2, T3, and T4 (with precipitates) is mainly due to grain-boundaries hardening $\left(\Delta \sigma_{\mathrm{G}}\right)$, precipitation hardening $\left(\Delta \sigma_{\mathrm{p}}\right)$, and dislocation hardening $\left(\Delta \sigma_{\mathrm{dis}}\right)$. Therefore, the increase in the yield strengths of $\mathrm{T} 2, \mathrm{~T} 3$, and $\mathrm{T} 4$ can be derived from a simple function including the individual contributions, which can be expressed as $[8,38]$ :

$\Delta \sigma_{0.2}=\Delta \sigma_{\mathrm{G}}+\Delta \sigma_{\mathrm{p}}+\Delta \sigma_{\mathrm{dis}}$.

Based on the classical Hall-Petch equation, $\Delta \sigma_{0.2}=\sigma_{0}+k d^{1 / 2}$, where $\sigma_{0}$ is the lattice friction, $k$ is the strengthening coefficient, and $d$ is the average grain size [2]. Thus, the increase in yield strength caused by the grain boundaries can be expressed as:

$\Delta \sigma_{\mathrm{G}}=k\left(d_{2}^{-1 / 2}-d_{1}^{-1 / 2}\right)$,

where $d_{1}$ and $d_{2}$ represent the different grain sizes. In the present study, the value of $k=226 \mathrm{MPa} \mu \mathrm{m}^{1 / 2}$ is adopted from the FeCoNiCrMn system [39]. Therefore, the $\Delta \sigma_{\mathrm{G}}$ for the T2, T3, and T4 were calculated to be $0.8,0.9$, and $159.8 \mathrm{MPa}$, respectively.

The strengthening caused by ordered coherent precipitates $\left(\Delta \sigma_{0}\right)$ is due to dislocation shearing in the ordered precipitates and the creation of an antiphase boundary (APB) on their glide plane, which impede the movement of dislocations [40]. Dislocation shearing of the precipitates was observed in the present study (Fig. 11). Therefore, three contributing factors for precipitation hardening should be considered, namely, particle-matrix coherency $\Delta \sigma_{\mathrm{CS}}$, modulus mismatch $\Delta \sigma_{\mathrm{MS}}$, and atomic ordering $\Delta \sigma_{\mathrm{OS}}$. The former two take place prior to the dislocation-shearing process whereas the latter one occurs during shearing. In principle, the precipitation hardening is determined by the larger of the two values between $\Delta \sigma_{\mathrm{CS}}+\Delta \sigma_{\mathrm{MS}}$ and $\Delta \sigma_{\mathrm{OS}} . \Delta \sigma_{\mathrm{CS}}, \Delta \sigma_{\mathrm{MS}}$, and $\Delta \sigma_{\mathrm{OS}}$ can be expressed as [41]:

$\Delta \sigma_{\mathrm{CS}}=M \cdot \alpha_{\varepsilon}(G \cdot \varepsilon)^{3 / 2}\left(\frac{r f}{0.5 G b}\right)^{1 / 2}$,

$\Delta G_{\mathrm{MS}}=M \cdot 0.0055 \cdot(\Delta G)^{3 / 2}\left(\frac{2 f}{G}\right)^{1 / 2}\left(\frac{r}{b}\right)^{3 m / 2-1}$,

$\Delta \sigma_{\mathrm{OS}}=M \cdot 0.81 \frac{\gamma_{\mathrm{APB}}}{2 b}\left(\frac{3 \pi f}{8}\right)^{1 / 2}$,

where $M$ is the Taylor factor (3.06 for the FCC matrix), $\alpha_{\varepsilon}=2.6$ for the FCC structure, $\varepsilon=2 / 3 \cdot(\Delta a / a)$ represents the matrix-precipitate misfit (with $\Delta a$ being the difference in lattice constant between the matrix and the precipitates and $a$ representing the lattice constant of the matrix), $m=$ $0.85, \Delta G$ is the different shear modulus between the precipitates and the matrix, $f$ is the volume fraction of the ordered precipitates, $r$ is the precipitate's radius, $b$ is the Burgers vector $\left(b=a_{0} / \sqrt{2}\right.$, with $a_{0}$ as the lattice constant of the ordered precipitates), and $\gamma_{\mathrm{APB}}$ is the APB energy [2]. The values of $\Delta G=4 \mathrm{MPa}$ and $\gamma_{\mathrm{APB}}=0.2 \mathrm{~J} \mathrm{~m}^{-2}$ adopted 
in present study were borrowed from the $\mathrm{Ni}_{3} \mathrm{Al}$ precipitates in Ni-based superalloys $[2,42]$. According to the above equations, the particle-matrix coherencies in the $\mathrm{T} 2$, T3, and T4 were calculated as 207.2, 184.3, and $240 \mathrm{MPa}$, respectively. The modulus mismatches in the $\mathrm{T} 2, \mathrm{~T} 3$, and $\mathrm{T} 4$ were calculated to be $27.1,64.4$, and 85.2 $\mathrm{MPa}$, respectively. The calculated $\Delta \sigma_{\mathrm{OS}}$ are 407.5, 479 , and $534 \mathrm{MPa}$, respectively. Since the contributions from $\Delta \sigma_{\mathrm{CS}}$ and $\Delta \sigma_{\mathrm{MS}}$ are smaller than that from $\Delta \sigma_{\mathrm{OS}}$, the ordering strengthening determines the resultant contribution of precipitation hardening.

In the case of the T4, the non-recrystallized region has a high KAM value and a large number of low angle boundary misorientations, which indicates that the dislocations are not completely eliminated during the annealing process. The dislocations then interact with each other and impede their motion during deformation. The increment in dislocation hardening can be expressed using the Bailey-Hirsch formula [2]:

$\Delta \sigma_{\mathrm{dis}}=M \alpha G b \rho^{1 / 2}$,

where $\alpha$ is a constant for FCC metals ( $\alpha=0.2), \rho$ represents the dislocation density, and $G=74 \mathrm{GPa}$ is the shear modulus adopted from the FeCoNiCrMn system. The dislocation density was roughly estimated using the Williamson-Hall method, which can be expressed as [43]:

$\beta \cos \theta=k \lambda / D+(4 \sin \theta) \cdot \varepsilon$,

where $\beta$ is the peak broadening determined from the $\mathrm{XRD}$ data, $k$ is a constant $(\sim 0.9), \lambda$ is the wavelength of $\mathrm{Cu}$ Ka radiation $(0.15405 \mathrm{~nm}), D$ represents the crystallite size, $\varepsilon$ stands for the microstrain, and $\theta$ is the Bragg angle of a certain diffraction peak. The linear fit of $\beta \cos \theta-4 \sin \theta$ is shown in Fig. S2. The slope stands for the $\varepsilon$ parameter, which has a value of 0.13513 . The dislocation density $(\rho)$ can be derived from the following equation [44]:

$\rho=2 \sqrt{3} \cdot \varepsilon /(D b)$.

Using this equation, the dislocation density was calculated to be $1.31 \times 10^{15} \mathrm{~m}^{-2}$. Hence, taking this value into Equation (11), the yield-strength increment in the T4 caused by dislocation hardening is determined to be $401 \mathrm{MPa}$. The Tl, T2, and T3 present a fully recrystallized structure and the TEM bright-field image of the T2 (Fig. S3) shows very few dislocations. Therefore, the strengthening contribution by dislocation can be negligible in the T1, T2, and T3.

Based on the above analysis, the yield strengths in the $\mathrm{T} 2$, T3, and $\mathrm{T} 4$ are calculated as $746.6,818.2$, and 1433.1 MPa, respectively. For clarity, a column chart is shown in Fig. 12, which indicates that the calculated va-

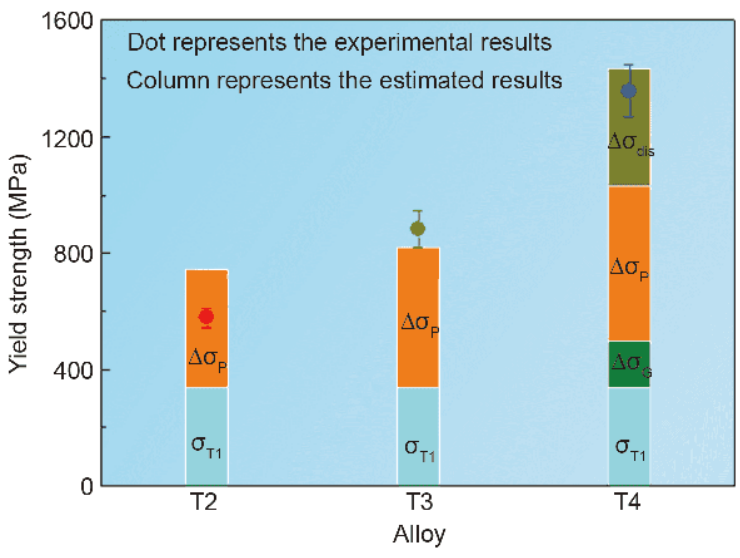

Figure 12 A column chart characterizing the strengthening contributions of different mechanisms, where $\Delta \sigma_{\mathrm{p}}, \Delta \sigma_{\mathrm{G}}$, and $\Delta \sigma_{\text {dis }}$ represent the precipitation hardening, grain-boundaries hardening, and dislocation hardening, respectively.

lues are in reasonable agreement with the experimentally determined ones (marked by the red, green, and blue dots, respectively). It should be noted that these estimations of the contributions of the individual hardening mechanisms cannot be absolutely accurate because the relevant parameters (e.g., the strengthening coefficient $k$, APB energy, and shear modulus) are either roughly estimated or adopted from superalloys. Nevertheless, these estimates can provide a reasonable reference for analyzing the contributions of the individual hardening mechanisms. According to the results, precipitation hardening plays a dominant role in the increment of the yield strength.

\section{CONCLUSION}

In the present study, the CALPHAD method was applied to guide the design of the $(\mathrm{FeCoNi})_{92} \mathrm{Al}_{2.5} \mathrm{Ti}_{5.5}$ HEA strengthened by precipitation hardening. The phase-precipitation, microstructural-evolution, and strengthening mechanisms were discussed. The following conclusions can be drawn:

(1) Uniformly dispersed precipitates having an $\mathrm{L1}_{2}$ ordered structure and forming a fully coherent interface with the FCC matrix were obtained by a proper aging treatment. The experimental results agree well with the CALPHAD-predicted results.

(2) Compared with the single-phase $\mathrm{T} 1$, the yield strength increases from 338.3 to $1355.9 \mathrm{MPa}$ and the ultimate tensile strength increases from 759.3 to 1488.1 MPa upon tailoring the size and volume fraction of the precipitates, as well as the size of the grains, while the elongation maintains a reasonable value of $8.1 \%$. The 
impressive enhancement of the strength is mainly due to precipitate hardening. The strengthening contributions by precipitation in the $\mathrm{T} 2, \mathrm{~T} 3$, and $\mathrm{T} 4$ are $407.5,479$, and $534 \mathrm{MPa}$, respectively.

(3) A pronounced planar glide and well-developed MBs were observed in both alloys without and with precipitates at low and high strain, respectively. The deformation-induced MBs and the coherent precipitates sheared by dislocations correspond to the deformation and strengthening mechanisms, which contribute to the combination of good ductility and high strength in the present alloy.

\section{Received 20 June 2019; accepted 27 August 2019;} published online 17 September 2019

1 Zhang Y, Zuo TT, Tang Z, et al. Microstructures and properties of high-entropy alloys. Prog Mater Sci, 2014, 61: 1-93

2 He JY, Wang H, Huang HL, et al. A precipitation-hardened highentropy alloy with outstanding tensile properties. Acta Mater, 2016, 102: 187-196

3 Zhang W, Liaw PK, Zhang Y. Science and technology in highentropy alloys. Sci China Mater, 2018, 61: 2-22

4 Zhao YL, Yang T, Tong Y, et al. Heterogeneous precipitation behavior and stacking-fault-mediated deformation in a CoCrNibased medium-entropy alloy. Acta Mater, 2017, 138: 72-82

5 Ming K, Bi X, Wang J. Precipitation strengthening of ductile $\mathrm{Cr}_{15} \mathrm{Fe}_{20} \mathrm{Co}_{35} \mathrm{Ni}_{20} \mathrm{Mo}_{10}$ alloys. Scripta Mater, 2017, 137: 88-93

6 He F, Chen D, Han B, et al. Design of D022 superlattice with superior strengthening effect in high entropy alloys. Acta Mater, 2019, 167: 275-286

7 Wang Z, Baker I, Cai Z, et al. The effect of interstitial carbon on the mechanical properties and dislocation substructure evolution in $\mathrm{Fe}_{40.4} \mathrm{Ni}_{11.3} \mathrm{Mn}_{34.8} \mathrm{Al}_{7.5} \mathrm{Cr}_{6}$ high entropy alloys. Acta Mater, 2016, 120: $228-239$

8 Guo L, Ou X, Ni S, et al. Effects of carbon on the microstructures and mechanical properties of FeCoCrNiMn high entropy alloys. Mater Sci Eng-A, 2019, 746: 356-362

$9 \mathrm{Li} \mathrm{Z}$. Interstitial equiatomic $\mathrm{CoCrFeMnNi}$ high-entropy alloys: carbon content, microstructure, and compositional homogeneity effects on deformation behavior. Acta Mater, 2019, 164: 400-412

10 Li Z, Pradeep KG, Deng Y, et al. Metastable high-entropy dualphase alloys overcome the strength-ductility trade-off. Nature, 2016, 534: 227-230

11 Sun SJ, Tian YZ, An XH, et al. Ultrahigh cryogenic strength and exceptional ductility in ultrafine-grained $\mathrm{CoCrFeMnNi}$ high-entropy alloy with fully recrystallized structure. Mater Today Nano, 2018, 4: 46-53

12 Yang T, Zhao YL, Tong Y, et al. Multicomponent intermetallic nanoparticles and superb mechanical behaviors of complex alloys. Science, 2018, 362: 933-937

13 Liu WH, Lu ZP, He JY, et al. Ductile CoCrFeNiMo high entropy alloys strengthened by hard intermetallic phases. Acta Mater, 2016, 116: $332-342$

14 Zhang YH, Li M, Godlewski LA, et al. Effective design of new austenitic cast steels for ultra-high temperature automotive exhaust components through combined CALPHAD and experimental ap- proaches. Mater Sci Eng-A, 2017, 683: 195-206

15 Senkov ON, Zhang C, Pilchak AL, et al. CALPHAD-aided development of quaternary multi-principal element refractory alloys based on NbTiZr. J Alloys Compd, 2019, 783: 729-742

16 He JY, Wang $\mathrm{H}, \mathrm{Wu}$ Y, et al. Precipitation behavior and its effects on tensile properties of $\mathrm{FeCoNiCr}$ high-entropy alloys. Intermetallics, 2016, 79: 41-52

17 Callister Jr WD. Materials Science and Engineering, 6th ed. New York: John Wiley \& Sons, 2003

18 Trotter G, Rayner G, Baker I, et al. Accelerated precipitation in the AFA stainless steel $\mathrm{Fe}-20 \mathrm{Cr}-30 \mathrm{Ni}-2 \mathrm{Nb}-5 \mathrm{Al}$ via cold working. Intermetallics, 2014, 53: 120-128

19 Lucas MS, Wilks GB, Mauger L, et al. Absence of long-range chemical ordering in equimolar FeCoCrNi. Appl Phys Lett, 2012, 100: 251907

20 Zhang JL, Tasan CC, Lai MJ, et al. Partial recrystallization of gum metal to achieve enhanced strength and ductility. Acta Mater, 2017, 135: 400-410

21 Ming K, Bi X, Wang J. Realizing strength-ductility combination of coarse-grained $\mathrm{Al}_{0.2} \mathrm{Co}_{1.5} \mathrm{CrFeNi}_{1.5} \mathrm{Ti}_{0.3}$ alloy via nano-sized, coherent precipitates. Int J Plast, 2018, 100: 177-191

22 Gerold V, Karnthaler HP. On the origin of planar slip in f.c.c. alloys. Acta Metall, 1989, 37: 2177-2183

23 Yoo JD, Hwang SW, Park KT. Origin of extended tensile ductility of a Fe-28Mn-10Al-1C steel. Metall Mat Trans A, 2009, 40: 15201523

24 Gutierrez-Urrutia I, Raabe D. Multistage strain hardening through dislocation substructure and twinning in a high strength and ductile weight-reduced Fe-Mn-Al-C steel. Acta Mater, 2012, 60: 5791-5802

25 Hughes DA. Microstructural evolution in a non-cell forming metal: Al-Mg. Acta Metall Mater, 1993, 41: 1421-1430

26 Olfe J, Neuhäuser H. Dislocation groups, multipoles, and friction stresses in $\alpha$-CuZn alloys. Phys Stat Sol (a), 1989, 109: 149-160

27 Yang X, Zhang Y. Prediction of high-entropy stabilized solid-solution in multi-component alloys. Mater Chem Phys, 2012, 132: 233-238

28 Fu Z, Jiang L, Wardini JL, et al. A high-entropy alloy with hierarchical nanoprecipitates and ultrahigh strength. Sci Adv, 2018, 4: eaat 8712

29 Takeuchi A, Inoue A. Classification of bulk metallic glasses by atomic size difference, heat of mixing and period of constituent elements and its application to characterization of the main alloying element. Mater Trans, 2005, 46: 2817-2829

30 Zhao S, Stocks GM, Zhang Y. Stacking fault energies of face-centered cubic concentrated solid solution alloys. Acta Mater, 2017, 134: $334-345$

31 Murr LE, Ayala A, Niou CS. Microbands and shear-related microstructural phenomena associated with impact craters in 6061T6 aluminum. Mater Sci Eng-A, 1996, 216: 69-79

32 Wang Z, Baker I, Guo W, et al. The effect of carbon on the microstructures, mechanical properties, and deformation mechanisms of thermo-mechanically treated $\mathrm{Fe}_{40.4} \mathrm{Ni}_{11.3} \mathrm{Mn}_{34.8} \mathrm{Al}_{7.5} \mathrm{Cr}_{6}$ high entropy alloys. Acta Mater, 2017, 126: 346-360

33 Otto F, Dlouhý A, Somsen C, et al. The influences of temperature and microstructure on the tensile properties of a $\mathrm{CoCrFeMnNi}$ high-entropy alloy. Acta Mater, 2013, 61: 5743-5755

34 Yoo JD, Park KT. Microband-induced plasticity in a high Mn-Al-C light steel. Mater Sci Eng-A, 2008, 496: 417-424

35 Wang Z, Baker I. Effects of annealing and thermo-mechanical 
treatment on the microstructures and mechanical properties of a carbon-doped FeNiMnAl multi-component alloy. Mater Sci EngA, 2017, 693: 101-110

36 Guo L, Xiao D, Wu W, et al. Effect of Fe on microstructure, phase evolution and mechanical properties of $(\mathrm{AlCoCrFeNi})_{100-x} \mathrm{Fe}_{x}$ high entropy alloys processed by spark plasma sintering. Intermetallics, 2018, 103: 1-11

37 Ma Y, Wang Q, Jiang BB, et al. Controlled formation of coherent cuboidal nanoprecipitates in body-centered cubic high-entropy alloys based on $\mathrm{Al}_{2}(\mathrm{Ni}, \mathrm{Co}, \mathrm{Fe}, \mathrm{Cr})_{14}$ compositions. Acta Mater, 2018, 147: 213-225

38 Kamikawa N, Sato K, Miyamoto G, et al. Stress-strain behavior of ferrite and bainite with nano-precipitation in low carbon steels. Acta Mater, 2015, 83: 383-396

39 Liu WH, Wu Y, He JY, et al. Grain growth and the Hall-Petch relationship in a high-entropy $\mathrm{FeCrNiCoMn}$ alloy. Scripta Mater, 2013, 68: 526-529

40 Liang YJ, Wang L, Wen Y, et al. High-content ductile coherent nanoprecipitates achieve ultrastrong high-entropy alloys. Nat Commun, 2018, 9: 4063

41 Ardell AJ. Precipitation hardening. Metall Trans A, 1985, 16: 21312165

42 Kozar RW, Suzuki A, Milligan WW, et al. Strengthening mechanisms in polycrystalline multimodal nickel-base superalloys. Metall Mat Trans A, 2009, 40: 1588-1603

43 Williamson GK, Hall WH. X-ray line broadening from filed aluminium and wolfram. Acta Metall, 1953, 1: 22-31

44 Zhao YH, Liao XZ, Jin Z, et al. Microstructures and mechanical properties of ultrafine grained $7075 \mathrm{Al}$ alloy processed by ECAP and their evolutions during annealing. Acta Mater, 2004, 52: 45894599

Acknowledgements This work was supported by the Fundamental Research Funds for the Central Universities of Central South University (2019zzts052) and the National Natural Science Foundation of China (51828102)

Author contributions Song M designed the project. Guo L and Gong $\mathrm{X}$ produced the materials and performed the mechanical testing. Guo L, $\mathrm{Gu}$ J, and Ni S conducted the microstructural characterization. Guo L, $\mathrm{Gu} \mathrm{J}$ and Song M wrote the manuscript. All authors contributed to the discussion of the results and commented on the manuscript.

Conflict of interest The authors declare no conflict of interest.

Supplementary information online version of this paper.

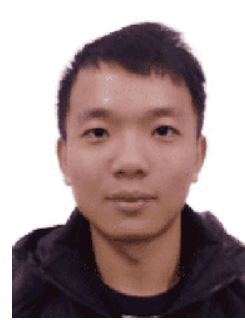

Lin Guo is currently a $\mathrm{PhD}$ candidate at Powder Metallurgy Research Institute, Central South University, China. His current research focuses on HEAs designing and microstructural evolution.

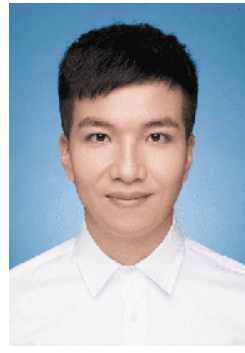

Ji Gu is a lecturer of Powder Metallurgy Research Institute, Central South University, China. He received his $\mathrm{PhD}$ degree in material science and engineering in 2019 under the supervision of Prof. Min Song. His current research focuses on exploring the mechanical behaviour, deformation mechanism and structure-property relationship of HEAs and gradient structure materials.

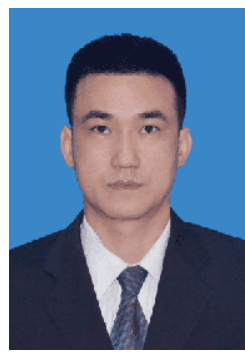

Min Song is a Professor and Vice Dean of Powder Metallurgy Research Institute at Central South University. He serves as Associate Editor of "Materials Characterization". He received his $\mathrm{PhD}$ degree in 2005 at Dartmouth College, USA. His current research interests involve deformation mechanisms of metallic materials, including: metals and alloys, bulk nanocrystalline materials, metallic glasses, HEAs and metal matrix composites.

\section{CALPHAD辅助设计高强度沉淀强化型高熵合金} 郭林 ${ }^{1}$, 顾及 ${ }^{1 *}$, 龚星 ${ }^{2}$, 倪颂 ${ }^{1}$, 宋旼 ${ }^{1^{*}}$

摘要 近年来, 设计具有高强度和优异延展性的高摘合金(HEAs)引 起了人们的广泛兴趣. 在本文中, 我们采用CALPHAD方法来设计 沉淀强化型 $(\mathrm{FeCoNi})_{92} \mathrm{Al}_{2.5} \mathrm{Ti}_{5.5}$ 高熵合金. 通过热机械处理过程来 调控合金晶粒尺寸、析出相大小及体积分数, 从而优化合金力学 性能. 在一定温度时效后, 具有 $L 1_{2}$ 有序结构的 $\mathrm{Ni}_{3}(\mathrm{Al}, \mathrm{Ti})$ 型第二相 在面心立方 (FCC)基体中均匀析出, 并与FCC基体共格. 通过热机 械处理过程, 合金的屈服强度从 $338.3 \mathrm{MPa}$ 增加到 $1355.9 \mathrm{MPa}$, 抗拉 强度从759.3 MPa增加到 $1488.1 \mathrm{MPa}$, 而伸长率仍然保持在 $8.1 \%$. 基 于分析模型定量评估屈服强度的增加, 结果表明屈服强度的显著 增加主要是由沉淀强化机制引起的. 变形引起的微观条带和位错 切过析出相是该合金的变形机制和强化机制，有助于该合金同时 具有优异的延展性和高强度. 本研究表明, CALPHAD方法可以为 高熵合金的设计和优化提供借鉴. 